DOI: $\underline{10.17805 / g g z .2021 .1 .3}$

\title{
Актер и педагог Юрий Владимирович Назаров. Штрихи к творческому портрету

\author{
В. А. Юркин
} \\ Московский гуманитарный университет
}

Педагогическое мастерство народного артиста России и профессора кафедры искусства Московского гуманитарного университета Юрия Владимировича Назарова вытекает из высокого профессионального уровня актера, его жизненного опыта и взглядов на события текущего времени. В жизни и в профессии мастер прошел большую и интересную школу, которая сформировала его как человека, актера и педагога. Многое в человеке закладывается с детства. Интересен момент выбора профессии и движения к иели.

Изучая биографические материалы и источники, мы видим, что у него было много сомнений в делах и поступках. Особенно это заметно по выбору профессии актера и учебе в театральном училище. Можно сделать вывод, что жизнь закалила и научила Ю. В. Назарова любить свою родину, иенить людей и быть верным призванию.

Ключевые слова: война; детство; дружба; выбор профессии; театр; роли в кино; мастерство; жизненная позиция; театральная педагогика; Ю. В. Назаров; российские актеры; советские актеры

\section{Actor and Teacher Yuri Vladimirovich Nazarov. Touches to a Creative Portrait}

V. A. Yurkin

Moscow University for the Humanities

The pedagogical skills of Yuri Vladimirovich Nazarov, the People's Artist of Russia and professor of the Department of Art at Moscow University for the Humanities, result from the high professional level of the actor, his life experience and views on current events. In his life and profession, the master has gone through a hard and interesting school of life, which formed him as a person, actor and teacher. Many things in a person's life depend on their childhood. The interesting moments are choosing an occupation and moving towards a goal.

Studying biographical materials and sources, we see that he had many doubts about his deeds and actions. This is especially noticeable in his choosing the profession of an actor and studying at a theater school. We can conclude that 
$Y u . V$. Nazarov's life has hardened and taught him to love our homeland, to appreciate people and to be faithful to the calling.

Keywords: war; childhood; friendship; career choice; theater; film roles; skills; life stance; theater pedagogy; Yu. V. Nazarov; Russian actors; Soviet actors

\section{ВВЕДЕНИЕ}

В биографии Юрия Владимировича Назарова есть очень примечательный эпизод. В день его рождения, 5 мая 1937 года, дедушка и бабушка подарили появившемуся на свет внуку книгу с произведениями Н. А. Некрасова. Поскольку имени еще новорожденному не придумали, то они подписали подарок так: «Нашему желанному, долгожданному внуку...». Будущий известный актер родился в Новосибирске, в семье студентов политехнического института, которые, окончив вуз в Томске, переехали в Новосибирск по распределению. Поскольку они были специалистами по тепловым агрегатам, то работали на ТЭЦ (Юрий Назаров, б/д: Электронный ресурс; Кожемяко, 2017: Электронный ресурс).

В нашей стране, у людей, проживающих за Уралом, другая житейская психология. Она базируется на том, что выжить в суровом климате Сибири и северных регионов можно сплотившись. Люди расположены друг к другу, готовы помочь и поддержать друг друга в трудных ситуациях. Новосибирск - это столица Сибирского края. Сегодня город по численности населения занимает третье место в России. Это крупный научный и культурный центр. Здесь работает Сибирское отделение Российской академии наук, существуют 17 профессиональных театров, открыты 17 музеев. Наличие в городе Театра оперы и балета говорит о многом. Работают 27 вузов и 8 филиалов иногородних учебных заведений (например, Новосибирская государственная консерватория им. М. И. Глинки, Новосибирский государственный театральный институт и другие вузы художественного профиля).

\section{ВОЕННОЕ ДЕТСТВО}

Творческий дебют перед публикой у Юрия Назарова состоялся в детстве, когда он участвовал в концертах для раненых в госпитале. В его репертуаре были стихи и песни. Ему говорили, что выступить надо так, чтобы боль у бойцов утихла, им стало бы легче. Маленького артиста ставили на стул, чтобы его всем лежащим в палате было видно. Юный артист очень старался с выражением читать стихи. Раненым такие концерты нравились, они дружно аплодировали. И это создавало новое желание выступать (Актер с необыкновенной харизмой ..., 2020: Электронный ресурс).

Юрий Владимирович Назаров - представитель поколения, у которого детство выпало на годы Великой Отечественной войны. Ему было четыре го- 
да, когда она началась. Он по-особому оценивает эти сложные годы. Много говорит о войне и победе, восхищаясь победителями. Его отец ушел на фронт и, к счастью, смог вернуться живым. Но прожил после Победы всего четыре года. Самый лучший подарок Юрию Назарову преподнесли бойцы Красной Армии в 1945 году. Ему 5 мая 1945 года исполнялось 8 лет. Накануне, 2 мая, был повержен Берлин, а 8 мая была объявлена Победа в Великой Отечественной войне. С тех пор и всю жизнь тема войны для Ю. В. Назарова остается святой. Он об этом много говорит, не меняя своей точки зрения (Тюрина, б/д: Электронный ресурс).

В 1944 г. Юрий Назаров пошел в первый класс. После войны учился в музыкальной школе. В седьмом классе у него появился настоящий друг, с которым они поддерживают дружеские отношения до сих пор, на протяжении уже более 70 лет. Речь идет о советском и российский писателе, публицисте, лауреате Государственной премий за достижения в области литературы Викторе Ивановиче Лихоносове. В 1954 г. они вместе окончили 73-ю мужскую среднюю школу Кировского района города Новосибирска.

Юрий Назаров как-то вспоминал, что в средней школе учителем русского языка и литературы был завуч Лев Николаевич Солуянов. Он проводил занятия в его классе, рассказывая на уроках о реализме в искусстве и литературе, обращаясь к «Слову о полку Игореве», связывал этот литературнохудожественный принцип не столько с социализмом, сколько с народным творчеством, со сказаниями и былинами (Назаров, 2008: 106).

\section{ПОСТУПЛЕНИЕ В ТЕАТРАЛЬНЫЙ ВУЗ}

В 1954 году Юрий Назаров с другом Виктором Лихоносовым решили вместе поступать в институт. Виктор хотел быть артистом, поэтому подбирал театральный вуз. Юрий Назаров готов был за компанию поехать вместе с ним. В итоге выбрали Щукинское театральное училище в Москве. Юрия Назарова приняли, а Виктора Лихоносова нет. Так друзьям пришлось расстаться (Тюрина, б/д: Электронный ресурс).

Вступительные экзамены в театральный вуз всегда вызывали большой общественный интерес. Известно, что многие выпускники, особенно выпускницы школы, мечтают о карьере артиста или артистки. Им хочется известности и славы. Многие из нас слышали истории поступления в театральные вузы. Иногда мечта осуществлялась, а порой и нет. Однако сложился определенный стереотип о том, что на вступительных экзаменах читают стихи, рассказывают басню или какой-либо рассказ. В своей книге «Только не о кино» Юрий Назаров раскрыл секрет своего поступления в Высшее театральное училище им. Б. В. Щукина в 1954 г. Вполне возможно, он прочитал стихи и рассказал басню. Но, как нам кажется, на решение приемной комиссии по- 
влияли его ответы на дополнительный, но очень важный мировоззренческий вопрос. Абитуриента Юрия Назарова спросили о том, какие у него остались театральные впечатления от родного города, где он рос и воспитывался. Здесь будущему студенту очень пригодился опыт сотрудничества с театром «Красный факел», когда он после 9-го класса утроился в театр рабочим сцены и поехал на гастроли в Москву. Он рассказал о спектаклях «Чайка», «Зыковы», «Бесприданница», «Село Степанчиково». Как вспоминает актер, это были впечатления о спектаклях по мировой и отечественной театральной классике. Оценили именно это: взгляды и суждения молодого человека на художественный процесс (Назаров, 2008: 98).

Первые учебные дни вызвали у студента Юрия Назарова и первые сомнения. Ему предложили читать отрывок из «Повести о настоящем человеке» Б. Н. Полевого, он размышлял о праве прикасаться к этому произведению. Сомнения усиливались. Он решил заработать право сеять «разумное, доброе, вечное» трудовой закалкой.

Благодаря дневниковым записям Юрий Владимирович Назаров вспомнил преподавателей театрального училища им. Б. В. Щукина. Он назвал их «дивными педагогами». Перечислил имена и предметы, которые они преподавали. Он вспомнил М. С. Беленького и Г. Г. Коган, которые работали на кафедре марксизма-ленинизма. Историю изобразительных искусств преподавал Б. Н. Сималин, зарубежную литературу - А. С. Поль, а историю русской литературы - П. И. Новицкий. По всему видно, что студент Ю. В. Назаров очень уважительно относился к преподавателям и запомнил их на всю оставшуюся жизнь. Более того, он посчитал возможным назвать имена педагогов в интервью. Это говорит о том, что интерес к учебе у него был. Видимо, учиться без Виктора Лихоносова ему не хотелось. Да, можно согласиться, что будущий мастер кино искал себя и смысл жизни (Алексинская, 2017: Электронный ресурс).

В 1954 г. режиссер Иван Пырьев снимал фильм «Испытание верности». По сюжету требовалось снять эпизод, когда молодые люди играют в футбол на спортивной площадке. Договорились, что снимать будут студентов Щукинского училища, которые занимаются физкультурой. Получилось так, что в день, когда была намечена съемка, занималась группа, в которой учился Юрий Назаров. Для первокурсников предстоящая съемка стала первой и они тщательно к ней готовились. Приехала съемочная группа во главе с помощником режиссера. Сняли эпизод. В ожидании фильма студенты активно обсуждали свой опыт. Как это часто бывает, фрагмент в фильм не вошел. 


\section{ТЕАТРАЛЬНЫЙ ВУЗ: ДУБЛЬ 2}

Спустя много лет, будучи не просто зрелым, а мудрым человеком, Юрий Назаров попытался самому себе объяснить, почему бросил Щукинское театральное училище, едва начав учиться. Он размышлял так: «Военный подранок, я не мог тогда понять, зачем мне это надо? Для меня искусство всегда было сродни проповедничеству. А я тогда не понимал, что и как я буду проповедовать. Жидковат был. Какие зерна туда нести и бросать, я тогда не понимал. Вот и ушел. Я сам себе не понравился» (цит. по: Ярошенко, 2016: Электронный ресурс).

Юрий Назаров был человеком впечатлительным. Начиналась «оттепель». Она переворачивала сознание молодого человека. На лекциях много говорили о том, что артисты должны знать жизнь, чтобы убедительно играть роли. В книге Ю. В. Назарова «Только не о кино» есть такая дневниковая запись: «22 июля 1955. 18 лет, период метаний и болтаний. Год, как окончили школу; я бросил театральное училище в Москве, проработал 4 месяца, с февраля по июнь, в Северном Казахстане на строительстве железнодорожных мостов, вернулся домой, к маме, в Новосибирск; друг В. Лихоносов год отработал учеником зуборезчика на заводе “Сибсельмаш". И тут двинули опять же с другом! - сдавать вступительные экзамены в Новосибирский сельхозинститут. В этом не столько тяги к сельскому хозяйству было - ее совсем не было, - сколько романтической гражданственности: надо идти к людям, в народ! Но не с пустыми же руками, а хотя бы специалистами сельского хозяйства» (Назаров, 2008). Вот такие юношеские зигзаги судьбы и неуверенности правильного выбора жизненного пути. Сегодня мы наблюдаем, что выпускникам школы непросто выбрать для себя профессию и устремленно учиться, зная, чего они хотят. Необходимо отметить, что выход книги Юрия Назарова заметили в литературном сообществе. Так, в «Литературной газете» была опубликована небольшая рецензия на книгу с анализом жизненных принципов популярного актера под названием «Кредо Юрия Назарова» (Пешкова, 2008: Электронный ресурс).

Вернулся в Новосибирск. В стране разворачивалось движение за освоение целинных земель. Он поехал в Казахстан и некоторое время работал на строительстве железнодорожных мостов. Затем вновь вернулся в Новосибирск и устроился на работу в строительную колонну. Затем поработал в одном из сибирских колхозов. Потом переехал на Дон и устроился помощником кузнеца. Наступил 1956 год. Юрий Назаров решил возвращаться в театральный вуз. В 1956 году он вновь зачисляется на первый курс Высшего театрального училища имени Б. В. Щукина.

Счастливый случай подвернулся студенту первого курса театрального училища Юрию Назарову в 1957 г. Ему была предложена роль рабочего в 
фильме режиссера Сергея Юткевича «Рассказы о Ленине». Фильм знаковый во многих отношениях. Прежде всего, тема не только историческая, но и политическая. Созвездие актеров предопределяло успех и победы на различных фестивалях. Для Юрий Назарова это был первый опыт участия в создании художественного фильма и общения с именитыми актерами. Это был без преувеличения мастер-класс для начинающего актера. Роль Владимира Ильича Ленина играл народный артист СССР, лауреат Ленинской премии, лауреат Государственных премий Максим Штраух. В фильме участвовали Олег Ефремов (Феликс Дзержинский), Всеволод Санаев (рабочий Николай Емельянов из Разлива), Геннадий Юхтин (Федор Мухин) и другие известные актеры (Назаров, 2008: 58).

\section{АКТЕРСКАЯ СУДЬБА}

Народный артист России Юрий Назаров снялся в 328 фильмах, среди которых «Трактир на Пятницкой», «Демидовы», «Отец Сергий». В большом списке ролей Юрий Владимирович выделяет роль Степана Жерехова в фильме «За облаками - небо». Этот фильм о летчиках-испытателях, которые, рискуя жизнью, учили «летать самолеты». Актер всегда реагировал на патриотическую тему, легко играл в таких фильмах, потому что это отвечало его взглядам и стремлениям. Он был и остается патриотом всей страны и своей малой родины (Прожога, 2015: Электронный ресурс).

Из всех фильмов, которые подарила судьба актеру Юрию Назарову, он по-особому относится к работе с режиссером Андреем Тарковским в фильме «Андрей Рублев». Фильм не только исторический, но и философский. По характеру это психологическая драма об образе жизни власти имущих в России средних веков. Фильм основан на истории жизни иконописца Андрея Рублева. Его портрет вписан жизнь и быт Руси начала XV в. Натуралистически, правдоподобно показана борьба за власть, княжеские междоусобицы, традиции язычества, набеги половцев. По замыслу режиссера необходимо было убедительно через образы героев воспроизвести череду исторических переплетений, через которую прошла матушка Россия на длинном пути своего развития. Без понимания сложной и жестокой истории трудно анализировать события прошедшего столетия.

В фильме «Андрей Рублев» Юрий Назаров блестяще сыграл две роли, два очень сложных образа князей Большого и Малого. По сценарию они похожи друг на друга как две капли воды. Одинаково заинтересованы о благе народа. Но у каждого из них есть политические интересы, они готовы на несоразмерную жестокость, чтобы удовлетворить непомерное тщеславие. И тот и другой способны на убийство, готовы нарушить произнесенную клятву. Психологическая драма с исторической матрицей произвела очень глубокое 
впечатление на зрителей. Фильм занял одно из самых почетных мест в истории отечественного и мирового кинематографа. Власть не приняла фильм, обвинив создателей в жестокости, мрачности и отсутствии патриотичности. Однако время все расставило по местам. На Каннском кинофестивале в 1969 г. фильм «Андрей Рублев» получил главный приз Международной федерации кинопрессы (ФИНПРЕССИ). Он не был представлен страной в основную программу. Представители властей не хотели показывать миру Россию, которая была представлена в фильме Тарковского (Солоницын, 2016: Электронный ресурс).

В 2008 г. Юрий Владимирович Назаров выпустил уже упоминавшуюся выше книгу «Только не о кино». Ее выход в свет был в определенной степени закономерностью. Будущий мастер кинематографического искусства с семи лет вел дневник. Пришло время, и он посоветовал вести дневник своему внуку. В одно прекрасное время внук вернул эту идею дедушке и обосновал смыл ведения дневника написанием в будущем книги. Так или иначе, мысль написать автобиографическую книгу, видимо, возникла у Юрия Владимировича накануне своего 70-летия. В итоге книга «Только не о кино» была издана в 2008 г. С опозданием на год, но всем опытным людям известно, насколько сложным является подготовка подобного издания. Текст, редакционная обработка, корректорская правка, подготовка макета, согласование и т. д. Вполне возможно, что Юрий Владимирович был на съемках. Какие-то этапы могли затянуться. Однако задача была выполнена, книга вышла в свет. Она написана необычно. В основе лежат дневниковые записи. Чем более ранний период записей, тем они интереснее. Есть много отступлений со ссылкой на интересные мысли великих писателей, философов, деятелей искусства и т. д. (Пешкова, 2008: Электронный ресурс).

Эта книга, помимо всего прочего, помогает уточнить некоторые хронологические сюжеты из жизни Юрия Владимировича Назарова. Например, в различных интервью называются разные даты его учебы на первом курсе в Щукинском театральном училище. Судя по дневниковым записям, приведенным в книге, он встречал Новый 1955-й год в Москве. Как известно, январь - это уже время сессии. В некоторых источниках можно найти упоминание, что его отговаривали бросать учебу и предлагали сдать экзамены, чтобы потом можно было восстановиться. Но он к этому совету не прислушался. Уехал в Новосибирск, где на заводе работал его друг Виктор, и также устроился туда на работу. Только спустя некоторое время уволился и уехал в Казахстан (Назаров, 2008: 48).

Вернемся в наше время. Театр, театральное искусство, театральные постановки для Московского гуманитарного университета - дело привычное. Еще в 2000 г. народный артист России, режиссер и актер Театра на Таганке 
Валерий Золотухин был приглашен в университет для создания студенческого театра. Среди студентов всегда были энтузиасты театрального дела. Поэтому студенческий театр МосГУ был создан, начался творческий процесс. Со временем театр стал называться студенческий театр-студия «Вокруг» (см.: Бородай, Первозванская, 2019). Каждый год начинался новый театральный сезон, собирался костяк студентов старших курсов и объявлялся прием новых артистов. За учебный год ставилось два-три спектакля, проходили премьеры. Когда в 2010 г. создавался факультет культуры и искусства, то в нем значилось направление подготовки специалитета 52.05.01 - «Актерское искусство», с квалификацией «Артист драматического театра и кино».

\section{ТЕАТРАЛЬНАЯ ПЕДАГОГИКА}

В 2015 г. Юрия Владимировича Назарова пригласили в Московский гуманитарный университет преподавать актерское мастерство на кафедре культуры и искусства, которую возглавлял кандидат педагогических наук, доцент, заслуженный работник культуры РФ А. А. Чванов. Заведующий кафедрой имел большой опыт подготовки различных культурных программ, взаимодействия с творческими организациями, в том числе с Гильдией актеров кино, в которой директором работала В. А. Гущина. Поиск педагога по актерскому мастерству он решил начать с Гильдии актеров кино и обратился с просьбой рекомендовать кого-нибудь из актеров. Через некоторое время Валерия Александровна назвала имя народного артиста РФ Юрия Владимировича Назарова. А. А. Чванов встретился с Ю. В. Назаровым для обсуждения будущего сотрудничества. Юрий Владимирович выразил готовность преподавать, но поставил одно условие. Он предложил, учитывая опыт некоторых творческих вузов, пригласить не только его, но и заслуженную артистку России Людмилу Васильевну Мальцеву. Он предложил курс актерского мастерства вести двум педагогам, полагая, что его могут приглашать на съемки, а учебный процесс в этом случае страдать не должен. Логика в таких рассуждениях была. Поэтому на кафедре культуры и искусства МосГУ появился не только творческий, но и педагогический дуэт.

Творческий дуэт актеров Людмилы Мальцевой и Юрия Назарова образовался в 1994 г. Они вместе играли в фильмах «Казачья быль» и «Затеси». Подготовили несколько музыкально-драматических программ и выступали перед зрителями на сценах различных городов России. Юрий Владимирович играл на гитаре. Они пели дуэтом и по одному. Рассказывали различные истории из своей творческой жизни.

Людмила Васильевна Мальцева (1950-2019) окончила Высшее театральное училище им. М. С. Щепкина. Училась у народного артиста СССР Михаила Ивановича Царева. В дальнейшем увлеклась изучением культуры и 
быта русского казачества, сохранения его в период эмиграции во Франции. С этой целью Л. В. Мальцева поступила на учебу в Сорбонну для изучения культуры казачьей эмиграции в начале XX в.

Актриса Людмила Мальцева сыграла около 40 ролей в фильмах и сериалах. Она снималась в самых разнообразных жанрах. В ее фильмографии можно отметить такие картины, как «Гражданский брак», «Мой любимый папа», «Бывших не бывает», «Пасечник», «Мы с дедушкой», «Здравствуй, Гриша». К сожалению, роль секретаря мэра в комедийном сериале «Домашний арест» стала для нее последней.

Л. В. Мальцева закончила аспирантуру, работала культурологом-исследователем и преподавала сценическую речь и актерское мастерство во ВГИКе. Владела несколькими языками: французским, немецким, украинским, сербским. Она хорошо исполняла романсы, эстрадные и классические песни. Это была талантливая и образованная женщина.

В сентябре 2015 г. педагоги пришли на первое занятие в МосГУ. На них смотрели 20 пар горящих глаз. Занятия начались со знакомства и разговора о профессии. Обсуждали образы героев в спектаклях и кино. Важно было заинтересовать студентов в изучении своей профессии. Необходимо знать творчество классиков мировой и отечественной литературы. Обязательно изучать произведения А. С. Грибоедова, М. Ю. Лермонтова, Н.В.Гоголя, А. Н. Островского, А. П. Чехова, М. М. Зощенко и других классиков драматургии. Важно было на занятиях стимулировать интерес к истокам театрального искусства - творчеству К. С. Станиславского и В. И. НемировичаДанченко. Далее преподавание ведется на основе системы Станиславского. Во всем мире театр строится и живет на идеях гениального русского режиссера и реформатора.

Профессия артиста в системе образования передается от мастера к ученику. Здесь зачастую работает принцип «делай, как я». Творческий опыт народного артиста России Ю. В. Назарова и заслуженной артистки РФ Л. В. Мальцевой делает таких педагогов уникальными. Опыт мастеров, безусловно, может распознать природные актерские данные у студентов. В процессе занятий выявляются особенности творческого воображения и темперамента будущего артиста, способность к образному мышлению. На занятиях по актерскому мастерству закладываются составляющие артистической индивидуальности, которые выявляются и профессионализируются в процессе обучения. Способность убедительно сыграть роль зачастую зависит от личных качеств и жизненного опыта актера. Необходимо правдиво отобразить в постановке художественную реальность произведения, замысел режиссера.

Для занятий по актерскому мастерству был выделен актовый зал первого учебного корпуса. Здесь имеется театральная, глубокая сцена с удобны- 
ми кулисами. По мере взросления студентов, роста их профессионального уровня в качестве учебных спектаклей брались классические и современных пьесы. Распределялись роли, отрабатывались мизансцены, репетировались фрагменты спектаклей.

\section{ЮБИЛЕЙ МАСТЕРА}

В Московском гуманитарном университете 2 ноября 2017 г. прошла творческая встреча, посвященная 80-летию народного артиста России, актера советского и российского кино, профессора факультета культуры и искусства МосГУ Юрия Владимировича Назарова. Мастера пришли поздравить друзья и коллеги. Народная артистка РСФСР, советская и российская актриса Зинаида Георгиевна Кириенко поздравила юбиляра теплыми словами: «Хотелось бы пожелать ему того, чтобы его жизненный путь длился еще долго и был интересен, эмоционален, чтобы каждый день становился новым вдохом, который позволит ему зажигаться снова и снова» (цит. по: В МосГУ прошла ..., 2017: Электронный ресурс). Юрия Владимировича также поздравили заслуженный артист РФ композитор Игорь Наджиев, актер театра и кино Сергей Горобченко и известная певица доцент кафедры культуры и искусства МосГУ Мари Карне.

Ректор университета профессор Игорь Михайлович Ильинский наградил Юрия Владимировича орденом «Служение и Честь»: «В своей профессии Юрий Владимирович добился высочайших достижений. Я горжусь тем, что этот человек является профессором нашего университета. Он настоящий король роли» (цит. по: Берникова, 2017: Электронный ресурс). Юрий Владимирович был растроган. Он сказал: «Я просто счастлив, а что самое главное - атмосфера была душевная. Всем хотелось бы сказать огромное спасибо. Много было добрых слов, сюрпризов, встреч. От этого приятно и радостно больше всего - знать, что не зря работаешь и идешь верной дорогой» (цит. по: В МосГУ прошла ..., 2017: Электронный ресурс).

\section{ЗАКЛЮЧЕНИЕ}

За плечами Юрия Владимировича Назарова осталась большая творческая жизнь. На сцене и в кино прошли более 60 лет. Звание народного артиста предполагает народную любовь к тому, что делает актер. Он удостоен почетных званий и государственных наград. В 1984 г. стал заслуженным артистом РСФСР. В 2004 г. ему присвоили звание народного артиста России. По случаю юбилеев награждался Орденом Дружбы и Орденом Почета. В 1970 г. его наградили медалью «За доблестный труд. Награжден медалями «В ознаменование 100-летия со дня рождения Владимира Ильича Ленина», «Маршал Советского Союза Жуков», «90 лет Великой Октябрьской социали- 
стической революции». Актер получил ордена Русской православной церкви: Святого равноапостольного великого князя Владимира III степени, Святого благоверного князя Даниила Московского, Преподобного Сергия Радонежского II степени, Великомученика Феодора Стратилата.

Ю. В. Назаров осенью 2020 года тяжело заболел коронавирусом. Его госпитализировали в Коммунарку. В прессе появились тревожные сигналы с признаками надежды. Каждый день в популярных газетах, на сайтах в Интернете публиковалась информация о состоянии его здоровья. Две недели напряжения. Но сибирский характер не сдавался. Ему звонили из МосГУ, поддерживали морально. В итоге он победил болезнь. Об этом также писали многие газеты. Жизнь популярного актера интересна любителям кино. Он поправился, вернулся в университет (Либгардт, 2020: Электронный ресурс).

Вернулся таким же энергичным в движениях, откровенным в рассуждениях, в хорошем настроении. Юрий Владимирович пришел на занятия в Актовый зал, где его ждали студенты. Поприветствовал студентов и сказал: «Жизнь продолжается! Вернемся к нашей пьесе».

\section{СПИСОК ЛИТЕРАТУРЫ}

Актер с необыкновенной харизмой. Ему уже 83 года (2020) [Электронный ресурс] // Фильмы, театр, актеры | Яндекс.Дзен. 8 мая. URL: https://zen.yandex.ru/media/film teatr/akter-s-neobyknovennoi-harizmoi-emu-uje-

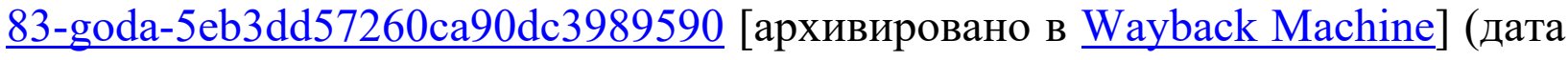
обращения: 05.02.2021).

Алексинская, М. (2017) «Нас спасёт коммунизм!» : беседа с народным артистом России Юрием Назаровым / М. Алексинская (корр.), Ю. В. Назаров [Электронный ресурс] // Завтра. 29 июня. URL: https://zavtra.ru/blogs/nas_spa syot_kommunizm [архивировано в Wayback Machine] (дата обращения: 05.02. 2021).

Берникова, Т. (2017) Артист Юрий Назаров получил награду [Электронный ресурс] // Сокольники и весь Восточный округ. 3 ноября. URL: https://www.vao-mos.info/territoriya-goroda/vao/artist-yurij-nazarov-poluchil-nag radu.html [архивировано в Wayback Machine] (дата обращения: 12.02.2021).

Бородай, А. Д., Первозванская, А. Б. (2019) Театр-студия «Вокруг» как элемент корпоративной культуры // Ученый совет. № 10 (178). С. 68-72.

В МосГУ прошла творческая встреча, посвященная Юрию Владимировичу Назарову (2017) [Электронный ресурс] // Московский гуманитарный университет. 3 ноября. URL: https://mosgu.ru/news/index.php?ID=35053 [архивировано в Wayback Machine] (дата обращения: 13.02.2021).

Кожемяко, В. (2017) «Коммунизм спасет нас, а индивидуализм погубит» : интервью / В. Кожемяко (корр.)., Ю. В. Назаров [Электронный ресурс] 
// Правда. № 29 (30526). 23 марта. URL: https://gazeta-pravda.ru/issue/2930526-23-marta-2017-goda/kommunizm-spasyet-nas-a-individualizm-pogubit/ [архивировано в Wayback Machine] (дата обращения: 12.02.2021).

Либгардт, О. (2020) «Помолитесь за него, пожалуйста»: знаменитый актер Юрий Назаров попал в реанимацию [Электронный ресурс] // Комсомольская правда. 8 сентября. URL: https://www.kp.ru/daily/217179/4284257/ [архивировано в Wayback Machine] (дата обращения: 12.02.2021).

Назаров, Ю. В. (2008) Только не о кино. М. : Алгоритм. 352 с.

Пешкова, В. (2008) Кредо Юрия Назарова [Электронный ресурс] // Литературная газета. № 38-39 (6190). 24 сентября. URL: https://lgz.ru/article/N3839--6190--2008-09-24-/Kr\%D0\%B5do-Yuriya-Nazarova5882/ [архивировано в Wayback Machine] (дата обращения: 12.02.2021).

Прожога, М. (2015) Актер Юрий Назаров: «Я совок, привыкший жить по совести» [Электронный ресурс] // Аргументы и факты в Омске : еженедельник. № 11. 11 марта. URL: https://omsk.aif.ru/culture/culture_person/14612 66 [архивировано в Wayback Machine] (дата обращения: 12.02.2021).

Солоницын, А. (2016) «Андрей Рублев»: жизнь и судьба киношедевра [Электронный ресурс] // Православие.Ru. 25 августа. URL: https://pravoslavie. ru/96427.html [архивировано в Wayback Machine] (дата обращения: 12.02. 2021).

Тюрина, К. (б/д) Юрий Назаров. Творческая биография [Электронный pecypc] // Русское кино. URL: https://www.russkoekino.ru/books/star/star0015.shtml [архивировано в Wayback Machine] (дата обращения: 10.02.2021).

Юрий Назаров (б/д) [Электронный ресурс] // Fam Person. URL: https://fam-person.ru/yurij-nazarov/ [архивировано в Wayback Machine] (дата обращения: 09.02.2021).

Ярошенко, А. (2016) «Цыц, жизнь продолжается!» Юрий Назаров мог стать агрономом или моряком, но выбрал «мужицкое» актерство [Электронный ресурс] // Российская газета — Неделя. № 291 (7159). 23 декабря. URL: https://rg.ru/2016/12/23/iurij-nazarov-schaste-kogda-ia-nikuda-ne-lezu-nikogo-nepihaiu.html [архивировано в Wayback Machine] (дата обращения: 10.02.2021).

Дата поступления: 15.02.2021 2.

\section{REFERENCES}

Akter s neobyknovennoi kharizmoi. Emu uzhe 83 goda [An actor of extraordinary charisma. He is already 83]. (2020) Fil'my, teatr, aktery | Yandex.Zen, May 8. [online] Available at: https://zen.yandex.ru/media/film teatr/akter-s-neobykno vennoi-harizmoi-emu-uje-83-goda-5eb3dd57260ca90dc3989590 [archived in Wayback Machine] (accessed 05.02.2021). (In Russ.). 
Aleksinskaia, M. (2017) «Nas spaset kommunizm!» : beseda s narodnym artistom Rossii Iuriem Nazarovym ["Communism will save us!": A conversation with the People's Artist of Russia Yuri Nazarov] / M. Aleksinskaia (corr.) and Yu. V. Nazarov. Zavtra, June 29. [online] Available at: https://zavtra.ru/blogs/nas spasyot kommunizm [archived in Wayback Machine] (accessed 05.02.2021). (In Russ.).

Bernikova, T. (2017) Artist Iurii Nazarov poluchil nagradu [Actor Yuri Nazarov received the award]. Sokol'niki $i$ ves' Vostochnyi okrug, November 3. [online] Available at: https://www.vao-mos.info/territoriya-goroda/vao/artist-yurijnazarov-poluchil-nagradu.html [archived in Wayback Machine] (accessed 12.02.2021). (In Russ.).

Borodai, A. D. and Pervozvanskaia, A. B. (2019) Teatr-studiia «Vokrug» kak element korporativnoi kul'tury [Studio theatre "Vokrug" as an element of corporate culture]. Uchenyi sovet, no. 10 (178), pp. 68-72. (In Russ.).

V MosGU proshla tvorcheskaia vstrecha, posviashchennaia Iuriiu Vladimirovichu Nazarovu [MosUH hosted a meet-the-artist session with Yuri Vladimirovich Nazarov] (2017) Moskovskii gumanitarnyi universitet [Moscow University for the Humanities], November 3. [online] Available at: https://mosgu.ru/news/ index.php?ID=35053 [archived in Wayback Machine] (accessed 13.02.2021). (In Russ.).

Kozhemiako, V. (2017) «Kommunizm spaset nas, a individualizm pogubit» ["Communism will save us, and individualism will destroy us"] : An interview / V. Kozhemiako (corr.). and Yu. V. Nazarov. Pravda, no. 29 (30526), March 23. [online] Available at: https://gazeta-pravda.ru/issue/29-30526-23-marta-2017goda/kommunizm-spasyet-nas-a-individualizm-pogubit/ [archived in Wayback Machine] (accessed 12.02.2021). (In Russ.).

Libgardt, O. (2020) «Pomolites' za nego, pozhaluista»: znamenityi akter Iurii Nazarov popal v reanimatsiiu ["Pray for him, please": The prominent actor Yuri Nazarov is in intensive care]. Komsomol'skaia pravda, September 8. [online] Available at: https://www.kp.ru/daily/217179/4284257/ [archived in Wayback Machine] (accessed 12.02.2021). (In Russ.).

Nazarov, Yu. V. (2008) Tol'ko ne o kino [Just not about cinema]. Moscow : Algoritm Publ. 352 p. (In Russ.).

Peshkova, V. (2008) Kredo Iuriia Nazarova [Yuri Nazarov's credo]. Literaturnaia gazeta, no. 38-39 (6190), September 24. [online] Available at: https://lgz.ru/article/N38-39--6190--2008-09-24-/Kr\%D0\%B5do-Yuriya-Nazarova 5882/ [archived in Wayback Machine] (accessed 12.02.2021). (In Russ.).

Prozhoga, M. (2015) Akter Iurii Nazarov: «Ia sovok, privykshii zhit' po sovesti» [Actor Yuri Nazarov: "I'm a Sov who got used to living according to my conscience"]. Argumenty i fakty $v$ Omske, no. 11, March 11. [online] Available at: 
https://omsk.aif.ru/culture/culture person/1461266 [archived in Wayback Machine] (accessed 12.02.2021). (In Russ.).

Solonitsyn, A. (2016) «Andrei Rublev»: zhizn' i sud'ba kinoshedevra [“Andrei Rublev": The story and fate of the masterpiece of cinematography]. Pravoslavie.Ru, August 25. [online] Available at: https://pravoslavie.ru/96427.html [archived in Wayback Machine] (accessed 12.02.2021). (In Russ.).

Tiurina, K. (s.d.) Iurii Nazarov. Tvorcheskaia biografiia [Yuri Nazarov. A creative biography]. Russkoe kino [online] Available at: https://www.russkoekino. ru/books/star/star-0015.shtml [archived in Wayback Machine] (accessed 10.02. 2021). (In Russ.).

Iurii Nazarov [Yuri Nazarov] (s.d.) Fam Person [online] Available at: https://fam-person.ru/yurij-nazarov/ [archived in Wayback Machine] (accessed 09. 02.2021). (In Russ.).

Yaroshenko, A. (2016) «Tsyts, zhizn' prodolzhaetsia!» Iurii Nazarov mog stat' agronomom ili moriakom, no vybral «muzhitskoe» akterstvo ["Hush, life still goes on!" Yuri Nazarov could have become an agronomist or a sailor, but he chose a "boorish" acting]. Rossiiskaia gazeta - Nedelia, no. 291 (7159), December 23. [online] Available at: https://rg.ru/2016/12/23/iurij-nazarov-schaste-kogda-ianikuda-ne-lezu-nikogo-ne-pihaiu.html [archived in Wayback Machine] (accessed 10.02.2021). (In Russ.).

Submission date: 15.02.2021 2.

Юркин Вячеслав Александрович - профессор кафедры искусства Московского гуманитарного университета, заслуженный работник культуры РФ. Тел.: +7 (916) 405-48-14. Эл. адрес: yurkin50@mail.ru

YURKIN, Vyacheslav Aleksandrovich, Professor, Department of Art, Moscow University for the Humanities, Honoured Cultural Worker of Russia. Tel.: +7 (916) 405-48-14. E-mail: yurkin50@mail.ru

Для цитирования:

Юркин В. А. Актер и педагог Юрий Владимирович Назаров. Штрихи к творческому портрету [Электронный ресурс] // Горизонты гуманитарного знания. 2021. № 1. С. 34-47. URL: https://journals.mosgu.ru/ggz/article/view/ 1367 (дата обращения: дд.мм.гггг). DOI: 10.17805/ggz.2021.1.3 